\title{
Prognostic Value of the mRNA Expression of Members of the Toll-like Receptor Family in Clear Cell Renal Cell Carcinoma
}

\author{
(1) Seda Sabah-Özcan ${ }^{1}$, (1) Payam Hacısalihoğlu², • Serdar Yanık³ \\ ${ }^{1}$ Bozok University Fakulty of Medicine, Department of Medical Biology, Yozgat, Turkey \\ 2 Istanbul Yeni Yüzyll University Fakulty of Medicine, Department of Pathology, Istanbul, Turkey \\ ${ }^{3}$ Bozok University Fakulty of Medicine, Department of Pathology, Yozgat, Turkey
}

\begin{abstract}
Objective: The aim of this study was to examine TLRs expression in tumoral and non-tumoral kidney tissue in patients with clear cell renal cell carcinoma (ccRCC) and to evaluate the prognostic significance of $T L R s$ expression profile in cCRCC.

Materials and Methods: TLR 1-10 mRNA expressions were measured by real-time polymerase chain reaction (RT-PCR) in formalin-fixed paraffinembedded (FFPE) 23 ccRCC tumoral tissue samples and 23 non-tumoral kidney tissue samples.

Results: A total of 46 individuals were included in the study. None of the patients had rhabdoid or sarcomatoid features. Lymphovascular invasion was observed in only three patients. RT-PCR analyses revealed TLRs mRNA expressions in 23 ccRCC samples and 23 non-tumoral FFPE kidney tissue samples. TLR (TLR1-10) mRNA expression was significantly increased in FFPE cCRCC tissues according to RT-PCR results ( $p<0.05)$.

Conclusion: The results demonstrated that TLRs might have function in $c c R C C$ pathogenesis. This present study will shed light on research to understand the role of the TLR gene family expression in tumor progression of ccRCC.
\end{abstract}

Keywords: RCC, TLR, mRNA expression

\section{Introduction}

Renal cell carcinoma (RCC) is the most common type of kidney cancer worldwide with an increasing incidence. During the diagnosis process, one third of the patients have metastasized and half of the remaining patients will experience a recurrence after treatment (1). Clear cell RCC (ccRCC) is the most frequent pathological subtype, representing approximately $70 \%$ of RCC cases (2). cCRCC has a poor prognosis with low response rates to conventional therapies such as chemotherapy (3).

Studies have shown that the most important genetic alteration in ccRCC is the loss of function of von Hippel-Lindau tumor suppressor (VHL) gene. In $90 \%$ of sporadic ccRCC, one copy of $V H L$ is mutated, while another copy is lost through $3 p$ deletions (4). According to The Cancer Genome Atlas, ccRCC is characterized by recurrent mutations in PI3K/AKT/MTOR (5). Tumor microenvironment has an important role in many processes observed in tumor progression, such as immuneescaping, chemotherapy resistance and metastasis. Recently, studies related to genetic changes in Toll-like receptors (TLRs) that recognize danger-associated molecular patterns derived from cancer cells in tumor microenvironment are increasing rapidly.

$T L R s$ are a conserved family of receptors capable of recognizing pathogenic structures known as pathogen-associated molecular patterns (6). Until today, 13 TLR analogues have been identified in mammals, TLR11, 12 and 13 are not expressed in humans but are functional only in mice (7). They are located on the cell surface or on endosomes within the cell. Although endosomal TLRs primarily detect viral and bacterial nucleic acids, surface TLRs such as TLR2 and TLR4 primarily recognize bacterial proteins (8). TLRs are mainly expressed in immune system cells such as macrophages and DCs, and are key sensors of pathogen invasion (9). Recent data suggest that functional TLRs are

Cite this article as: Sabah-Özcan S, Hacısalihoğlu P, Yanık S. Prognostic Value of the mRNA Expression of Members of the TLR Family in Clear Cell Renal Cell Carcinoma. Bull Urooncol 2019;18(4):149-153 
expressed not only in immune system cells but also in cancer cells (10). Damage-associated molecular patterns derived from damaged normal epithelial cells and necrotic cancer cells are found in the tumor microenvironment, and these patterns are thought to stimulate chronic inflammation by inducing specific TLRs $(11,12)$. However, the expression patterns of TLRs in human cancer tissues are largely unknown. To our knowledge, there is no previous study of TLRs (TLR1-10) mRNA expression in $\mathrm{CCRCC}$.

Thus, the aim of this study was to investigate $T L R 1-10$ expression in non-tumoral kidney tissue and tumoral tissue in patients with RCCs and to evaluate the prognostic significance of TLRs expression profile in cCRCCs.

\section{Materials and Methods}

\section{Study Samples}

Twenty-three tumoral ccRCC and 23 non-tumoral kidney tissue nephrectomy specimens were provided by İstanbul Gaziosmanpaşa Hospital. Patients were histopathologically diagnosed as having $\mathrm{CCRCC}$ at our hospital between 2007 and 2017. Cases with cystic RCC were excluded from our study since this subtype of RCC is composed of hypocellular tumor areas.

All patients were staged based on the Union for International Cancer Control Tumor-Node-Metastasis classification. The retrospective study design was approved by the Institutional Review Board (2017-KAEK-189_2018.10.10_02).

\section{Tumor Selection}

The histopathological slides stained with Hematoxylin-Eosin (H\&E) were microscopically examined to select paraffin embedded blocks with preserved, viable tumor tissue comprising over $90 \%$ of the block. The tumor area was marked and cut. Areas containing necrosis and hemorrhage were excluded from the study. Two pieces of $10-\mu \mathrm{m}$-thick sections were cut from each selected paraffin block.

\section{RNA Extraction and cDNA Synthesis}

Total RNA from $10 \mu \mathrm{m}$ Formalin-Fixed Paraffin-embedded (FFPE) sections was isolated using High Pure FFPET RNA isolation kit according to the manufacturer's instructions (Roche Diagnostics, Mannheim, Germany). Total RNA concentrations were measured and $1 \mu \mathrm{g}$ RNA was used as a template for the synthesis of complementary DNA (cDNA) using Transcriptor First Strand cDNA Synthesis Kit (Roche Diagnostics, Mannheim, Germany). The cDNAs were stored at $-80^{\circ} \mathrm{C}$ until used as a template in real-time quantitative PCR.

\section{Real-time Quantitative PCR}

Real-time PCR analyses were performed using quantitation of TLR1-10 genes and an internal reference gene ( $\beta$-actin) at mRNA level using the LightCycler 480 platform (Roche Diagnostics). PCR primers and Universal Probe Library probes for TLR1-10 and internal reference gene ( $\beta$-actin) are presented in Table 1. The final reaction volume for the analysis of TLRs expression was $20 \mu ; 1 \mu \mathrm{L}$ from each primer and probe set, $4 \mu$ of $\times 5$ LightCycler TaqMan Master Mix, $2 \mu$ cDNA sample, and
$13 \mu$ PCRgrade water. The cycle conditions were $95^{\circ} \mathrm{C}$ for 10 minutes, followed by 45 cycles at $95^{\circ} \mathrm{C}$ for 10 seconds, $60^{\circ} \mathrm{C}$ for 30 seconds, and $72^{\circ} \mathrm{C}$ for one second. All runs included one negative cDNA control consisting of DNase- and RNase-free water. The housekeeping $\beta$-actin gene was used as a control to normalize expression of each gene and the final results were obtained with LightCycler 480 software.

\section{Statistical Analysis}

SPSS 18 package program was used for statistical analysis. Non-parametric statistical methods were used to determine the differences between the groups. Mann-Whitney $U$ test was used for variables with two groups and Kruskal-Wallis $\mathrm{H}$ test was used when the number of groups was more than two. Values were expressed as mean \pm standard deviation. $p<0.05$ was considered statistically significant.

\begin{tabular}{|c|c|}
\hline Primer sequences & UPL number \\
\hline \multicolumn{2}{|l|}{ TLR1 } \\
\hline $\begin{array}{l}\text { СCTAGCAGTTATCACAAGCTCAAA (Forward) } \\
\text { CCTTGGGCCATTCCAAATA (Reverse) }\end{array}$ & \#79 (04689020001) \\
\hline \multicolumn{2}{|l|}{ TLR2 } \\
\hline $\begin{array}{l}\text { GGCCAGCAAATTACCTGTGTG (Forward) } \\
\text { AGGATCAGCAGGAACAGAGC (Reverse) }\end{array}$ & \#56 (04688538001) \\
\hline \multicolumn{2}{|l|}{ TLR3 } \\
\hline $\begin{array}{l}\text { GTGGCCCTTAAAAATGTGGA (Forward) } \\
\text { GTGTTTCCAGAGCCGTGCTAA (Reverse) }\end{array}$ & \#151 (04694376001) \\
\hline \multicolumn{2}{|l|}{ TLR4 } \\
\hline $\begin{array}{l}\text { TCATTGTCCTGCAGAAGGTG (Forward) } \\
\text { TCC CAC TCC AGG TAA GTG TT (Reverse) }\end{array}$ & \#62 (04688619001) \\
\hline \multicolumn{2}{|l|}{ TLR5 } \\
\hline $\begin{array}{l}\text { TGAGGGACTTTCTCATCTTCAAGT (Forward) } \\
\text { CCTTAATGCAGTCAGATGGCTA (Reverse) }\end{array}$ & \#31 (04687647001) \\
\hline \multicolumn{2}{|l|}{ TLR6 } \\
\hline $\begin{array}{l}\text { TTTGGATTTATCTCATAATCAGTTGC (Forward) } \\
\text { GATCTAAATGCCTGAAACTCACAA (Reverse) }\end{array}$ & \#121 (04693558001) \\
\hline \multicolumn{2}{|l|}{ TLR7 } \\
\hline $\begin{array}{l}\text { GTCTAAAGAACCTGGAAACTTTGG (Forward) } \\
\text { TCTCAGGGACAGTGGTCAGTT (Reverse) }\end{array}$ & \#102 (04692209001) \\
\hline \multicolumn{2}{|l|}{ TLR8 } \\
\hline $\begin{array}{l}\text { CAGAATAGCAGGCGTAACACATCA (Forward) } \\
\text { TGTTGTCATCATCATTCCACAA (Reverse) }\end{array}$ & \#59 (04688562001) \\
\hline \multicolumn{2}{|l|}{ TLR9 } \\
\hline $\begin{array}{l}\text { CTGGGACCTCTGGTACTGCT (Forward) } \\
\text { CTGCGTTTGTCGAAGACCA (Reverse) }\end{array}$ & \#98 (04692152001) \\
\hline \multicolumn{2}{|l|}{ TLR10 } \\
\hline $\begin{array}{l}\text { TGTCACCATTGTGGTTATTATGC (Forward) } \\
\text { GCAGATCAAAGTGGAGACAGC (Reverse) }\end{array}$ & \#76 (04688996001) \\
\hline \multicolumn{2}{|l|}{$\beta$-actin } \\
\hline $\begin{array}{l}\text { ATTGGCAATGAGCGGTTC (Forward) } \\
\text { CGTGGATGCCACAGGACT (Reverse) }\end{array}$ & \#11 (04685105001) \\
\hline
\end{tabular}




\section{Results}

A total of 46 individuals were included in the study. The mean age of the ccRCC group (six female and 17 male) and the control group (nine female and 14 male) was $58.4 \pm 7.5$ years (range, 48-72 years) and $56.3 \pm 6.9$ years (range, $45-70$ years), respectively. None of the patients had rhabdoid/sarcomatoid features. Lymphovascular invasion was observed in only three patients. The tumor characteristics are summarized in Table 2.

\begin{tabular}{|c|c|}
\hline Characteristics & Number of patients (\%) \\
\hline \multicolumn{2}{|l|}{ Gender } \\
\hline Female & $6(26)$ \\
\hline Male & $17(74)$ \\
\hline \multicolumn{2}{|l|}{ Affected side } \\
\hline Right & $12(52)$ \\
\hline Left & $11(48)$ \\
\hline \multicolumn{2}{|c|}{ Pathological grade } \\
\hline $\begin{array}{l}\text { Grade I } \\
\text { Grade II } \\
\text { Grade III } \\
\text { Grade IV }\end{array}$ & $\begin{array}{l}2(8) \\
7(30) \\
13(56) \\
1(6)\end{array}$ \\
\hline \multicolumn{2}{|l|}{ pT stage } \\
\hline pT1a & $7(30.4)$ \\
\hline pT1b & $8(34.7)$ \\
\hline pT2a & $1(4.5)$ \\
\hline pT3a & $7(30.4)$ \\
\hline \multicolumn{2}{|l|}{ Tumor size } \\
\hline$<5$ & $8(34.7)$ \\
\hline$\geq 5$ & $15(65.3)$ \\
\hline \multicolumn{2}{|l|}{ LN involvement } \\
\hline $\mathrm{Nx}$ & $5(21.7)$ \\
\hline $\begin{array}{l}\text { N0 } \\
\text { N1 }\end{array}$ & $\begin{array}{l}17(74) \\
1(4.3)\end{array}$ \\
\hline \multicolumn{2}{|c|}{ Capsular infiltration } \\
\hline Negative & $15(65.3)$ \\
\hline Positive & $8(34.7)$ \\
\hline \multicolumn{2}{|c|}{ Lymphovascular infiltration } \\
\hline Negative & $20(87)$ \\
\hline Positive & $3(14)$ \\
\hline \multicolumn{2}{|c|}{ Perirenal infiltration } \\
\hline Negative & $19(82.6)$ \\
\hline Positive & $4(17.4)$ \\
\hline \multicolumn{2}{|c|}{ Renal sinus infiltration } \\
\hline Negative & $19(82.6)$ \\
\hline Positive & $4(17.4)$ \\
\hline \multicolumn{2}{|l|}{ Necrosis } \\
\hline Negative & $16(69.5)$ \\
\hline Positive & $7(30.5)$ \\
\hline \multicolumn{2}{|c|}{ ccRCC: clear cell renal cell carcinoma, LN: Lymph node } \\
\hline
\end{tabular}

TLR (TLR1-10) mRNA expression was significantly increased in FFPE cCRCC tissues according to real time PCR results $(p<0.05)$ (Figure 1). There was no significant relationship between $T L R$ mRNA expression and tumor localization (right vs left kidney), tumor size, pT-class, capsular invasion, renal sinus invasion and necrosis ( $p>0.05)$. TLR5 overexpression in ccRCC tissue samples showed a significant association with tumor grade III ( $p=$ 0.028 ). In addition, a negative correlation was found between TLR1-4-7-9 expression and perirenal invasion, respectively $(p=0.023, p=0.041, p=0.041, p=0.031)$. TLR2 overexpression in cCRCC tissue samples showed a significant association with $\mathrm{Nx}$ category $(p=0.044)$.

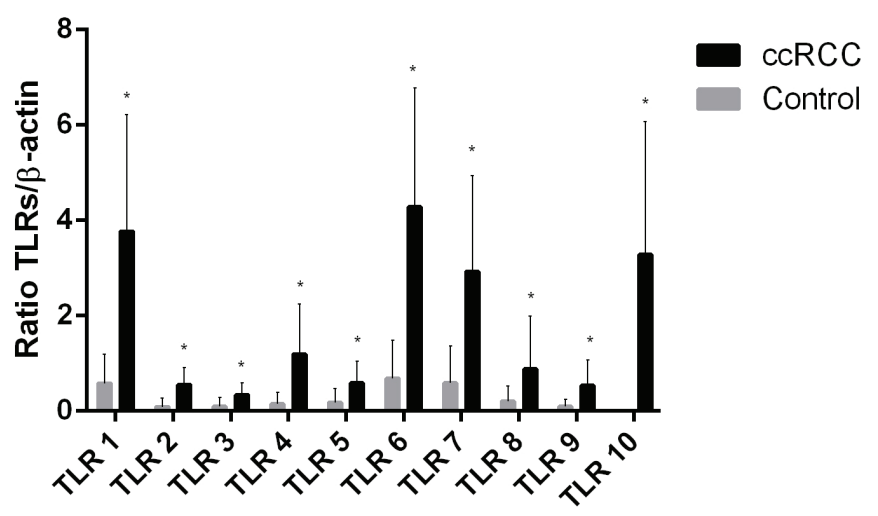

Figure 1. mRNA expression level of TLRs in FFPE kidney samples. All TLR mRNA expression was followed by real-time PCR and the results were normalized to $\beta$-actin mRNA. Values were expressed as mean \pm standard deviation. Asterisks $\left({ }^{*}\right)$ denote significant differences $(p<0.05)$

ccRCC: Clear cell renal cell carcinoma

\section{Discussion}

It is believed that TLRs play important roles in innate immunity; and chronic inflammation is one of the vital events in carcinogenesis. TLRs are expressed in macrophages, natural killer cells (NK), dendritic cells (DCs) and T cells. Today, it is known that TLRs are also expressed in cancer cells (13). For this reason, it is considered that $T L R$ gene expression profiles may be important markers in cancer development and progression.

Here we demonstrated for the first time that TLR1-10 mRNA is frequently expressed in FFPE kidney tissues in patients with ccRCCs. The expression of TLR 1-10 mRNA was significantly increased in RCC patients compared to the control group. There were differences in TLR expression in many cancers (14). TLR expression studies in CCRCC are quite limited in the literature. In the current study, TLR5 overexpression in cCRCC tissue samples showed a significant association with tumor grade III. Similarly, it was suggested that TLR5 expression had become more diffuse during the progression to dysplasia (15). Further studies are needed to clarify the true role of TLR5 expression in cCRCC.

Immunogenic processes are effective in the pathogenesis of RCC and RCC may affect different effector cells of the natural and adaptive immune system including NK cells, DCs and various $\mathrm{T}$ cells (16). Failure in desired full response to 
target-specific therapies has revived the interest in immune modulation in RCC treatment. The importance of the role of the immune response to RCC was understood when it was shown that metastatic lesions might regress spontaneously (17). Additionally, it was confirmed that there was a complex interaction between the tumor and host immune response with demonstration of increase in cytokines (18) and chemokines (19) as well as tumor-infiltrating lymphocytes (20) in circulation in patients with RCC.

Low levels of oxygen in the cellular environment occur in many pathophysiological conditions such as infection, inflammation, and solid tumor development (21). The relation of tumor microenvironment with RCC development can be explained especially with the production of proangiogenic factors, which end up with the hyperactivation of Hypoxia-Inducible Factor 1 (HIF-1) in lesions with VHL mutations (22). In one study, it was reported that TLR2 and TLR6 expressions were increased in hypoxia (23). Morikawa et al. showed that TLR3 expression was increased in cCRCC patients compared to the control group (24). For this reason, probably, some cytokines produced by cancer cells or by infiltrating immune cells may induce the TLR3 expression in ccRCCs.

TLR expression profiles have been investigated in many types of cancer. Some studies have shown that TLRs inhibit tumor growth, while others have indicated that they enhance tumor progression. In a study, Bednarczyk found that three proteins namely Dual specificity protein phosphatase 2, Interferon gamma and Eukaryotic initiation factor 4A-I (DUSP2, IFN $\gamma$, EIF4A1) were associated with TLR system, which differentiate early stages of colorectal cancer from healthy tissue (25). TLRs also play a critical role in the induction of colitis, which in consequence can lead to cancer. One study reported that chronic stress could increase the expression of TLR in the colonic mucosa (26). Furthermore, ovarian cancer cells showed overexpression of TLR2, TLR3, TLR4, and TLR5 $(27,28)$, while there was a high expression of TLR5 and TLR9 in human cervical cancer (29). The results underline the role of pathways associated with TLR activation in the pathogenesis of several cancers.

In line with these studies, TLR3 mRNA expression was found to be higher in cCRCC patients compared to the control group in our study. In a study that was conducted with the immunohistochemical technique by Wang et al.(30), it was reported that TLR4 expression was increased in RCC tissues compared to neighboring normal tissues. In another study that was conducted on RCC FFPE tissues, it was shown that TLR9 was associated with good prognosis and that low TLR9 expression was associated with short-term survival (1). In the present study, TLR1-4-7-9 expressions were increased in patients with no perirenal invasion, which is an aggressive clinicopathological parameter for cCRCC.

\section{Study Limitations}

The main limitation of our study was the small number of patients. In addition to the expression of mRNA, it would be appropriate to show protein expression in these tissues.

\section{Conclusion}

As a result, TLR mRNA expressions were significantly increased in cCRCC FFPE tissues compared to non-tumoral tissue samples. It is important to elucidate the potential mechanisms underlying the formation and progression of cCRCC to facilitate the identification of new prognostic markers and development of promising targeted strategies. For this reason, determining TLR protein expressions as well as mRNA expression and comparing these data with clinicopathological data in more patients will reveal the role of the changes in expression of $T L R$ genes in cCRCC pathogenesis.

\section{Ethics}

Ethics Committee Approval: The retrospective study design was approved by the Institutional Review Board (no: 2017-KAEK-189_2018.10.10_02).

Informed Consent: Retrospective study.

Peer-review: Internally and externally peer-reviewed.

\section{Authorship Contributions}

Concept: S.S.Ö., P.H., S.Y., Design: S.S.Ö., Data Collection or Processing: S.S.Ö., P.H., Analysis or Interpretation: S.S.Ö., P.H., S.Y., Literature Search: S.S.Ö., Writing: S.S.Ö.

\section{Acknowledgements}

Publication: The results of the study were not published in full or in part in form of abstracts.

Contribution: We would like to thank Bozok University Microbiology Laboratory for its contributions to this study.

Conflict of Interest: No conflict of interest was declared by the authors.

Financial Disclosure: The authors declared that this study received no financial support.

\section{References}

1. Ronkainen H, Hirvikoski P, Kauppila S, Vuopala KS, Paavonen TK, Selander KS, et al. Absent Toll-like receptor-9 expression predicts poor prognosis in renal cell carcinoma. Journal of experimental \& clinical cancer research: CR. 2011;30:84.

2. Dai J, Lu Y, Wang J, Yang L, Han Y, Wang Y, et al. A four-gene signature predicts survival in clear-cell renal-cell carcinoma. Oncotarget. 2016;7(50):82712-26. Epub 2016/10/26.

3. Milowsky MI, Nanus DM. Chemotherapeutic strategies for renal cell carcinoma. The Urologic clinics of North America. 2003;30(3):601-9,x.

4. Inamura K. Renal Cell Tumors: Understanding Their Molecular Pathological Epidemiology and the 2016 WHO Classification. Int J Mol Sci 2017;18.

5. Cancer Genome Atlas Research N. Comprehensive molecular characterization of clear cell renal cell carcinoma. Nature 2013;499:43-49.

6. Kawai T, Akira S. The role of pattern-recognition receptors in innate immunity: update on Toll-like receptors. Nature immunology 2010;11:373-384.

7. Lawless MW, Greene CM. Toll-like receptor signalling in liver disease: ER stress the missing link? Cytokine 2012;59:195-202.

8. Kawasaki T, Kawai T. Toll-like receptor signaling pathways. Front Immunol 2014;5:461. 
9. Miyake K. Innate immune sensing of pathogens and danger signals by cell surface Toll-like receptors. Semin Immunol 2007;19:3-10.

10. Ayari $\mathrm{C}$, Bergeron $\mathrm{A}$, LaRue $\mathrm{H}$, et al. Toll-like receptors in normal and malignant human bladders. J Urol 2011;185:1915-1921.

11. Sato $Y$, Goto $Y$, Narita N, Hoon DS. Cancer Cells Expressing Toll-like Receptors and the Tumor Microenvironment. Cancer Microenviron 2009;2 Suppl 1:205-214.

12. Bhatelia K, Singh K, Singh R. TLRs: linking inflammation and breast cancer. Cell Signal 2014;26:2350-2357.

13. Goutagny $\mathrm{N}$, Estornes $\mathrm{Y}$, Hasan $\mathrm{U}$, et al Targeting pattern recognition receptors in cancer immunotherapy. Target Oncol 2012;7:29-54.

14. Ridnour LA, Cheng RY, Switzer $\mathrm{CH}$, et al. Molecular pathways: tolllike receptors in the tumor microenvironment--poor prognosis or new therapeutic opportunity. Clin Cancer Res 2013;19:1340-1346.

15. Jouhi L, Renkonen S, Atula $T$, et al. Different Toll-Like Receptor Expression Patterns in Progression toward Cancer. Front Immunol 2014;5:638.

16. Geiger C, Nossner E, Frankenberger B, et al. Harnessing innate and adaptive immunity for adoptive cell therapy of renal cell carcinoma. J Mol Med (Berl) 2009;87:595-612.

17. Lokich J. Spontaneous regression of metastatic renal cancer. Case report and literature review. Am J Clin Oncol 1997;20:416-418.

18. Dosquet C, Schaetz A, Faucher $C$, et al. Tumour necrosis factoralpha, interleukin- 1 beta and interleukin- 6 in patients with renal cell carcinoma. Eur J Cancer 1994;30A:162-167.

19. Johrer K, Zelle-Rieser C, Perathoner A, et al. Up-regulation of functional chemokine receptor CCR3 in human renal cell carcinoma. Clin Cancer Res 2005; 11:2459-2465.

20. Thompson $\mathrm{RH}$, Dong $\mathrm{H}$, Lohse $\mathrm{CM}$, et al. PD-1 is expressed by tumor-infiltrating immune cells and is associated with poor outcome for patients with renal cell carcinoma. Clin Cancer Res 2007;13:1757-1761.
21. Imtiyaz HZ, Simon MC. Hypoxia-inducible factors as essential regulators of inflammation. Curr Top Microbiol Immunol 2010;345:105-120.

22. Rosa R, Damiano V, Formisano L, et al. Combination of a Toll-like receptor 9 agonist with everolimus interferes with the growth and angiogenic activity of renal cell carcinoma. Oncoimmunology 2013;2:e25123.

23. Kuhlicke J, Frick JS, Morote-Garcia JC, et al. Hypoxia inducible factor (HIF)-1 coordinates induction of Toll-like receptors TLR2 and TLR6 during hypoxia. PloS One 2007;2:e1364.

24. Morikawa T, Sugiyama A, Kume $H$, et al. Identification of Toll-like receptor 3 as a potential therapeutic target in clear cell renal cell carcinoma. Clin Cancer Res 2007; 13:5703-5709.

25. Bednarczyk M, Muc-Wierzgon M, Walkiewicz K, et al. Profile of gene expression of TLR-signaling pathways in colorectal cancer tissues. Int J Immunopathol Pharmacol 2017;30:322-326.

26. McKernan DP, Nolan A, Brint EK, et al. Toll-like receptor mRNA expression is selectively increased in the colonic mucosa of two animal models relevant to irritable bowel syndrome. PLoS One 2009;4:e8226.

27. Luo XZ, He QZ, Wang K. Expression of Toll-like receptor 4 in ovarian serous adenocarcinoma and correlation with clinical stage and pathological grade. Int J Clin Exp Med 2015;8:14323-14327.

28. Zhou M, McFarland-Mancini MM, Funk HM, et al. Toll-like receptor expression in normal ovary and ovarian tumors. Cancer Immunol Immunother 2009;58:1375-1385.

29. Kim WY, Lee JW, Choi JJ, et al. Increased expression of Toll-like receptor 5 during progression of cervical neoplasia. Int J Gynecol Cancer 2008;18:300-305.

30. Wang W, Zhao E, Yu Y, et al. MiR-216a exerts tumor-suppressing functions in renal cell carcinoma by targeting TLR4. Am J Cancer Res 2018;8:476-488. 